\title{
JOHN ILLMAN
}

special articles

\section{Training for interviews with the media}

Media training is designed to prepare people for print, radio and TV interviews. It is especially challenging to prepare psychiatrists for interviews with the media because reporting of issues related to mental health is often distorted and stigmatising. Although media coverage of women's rights, Black civil rights and disability has changed markedly, mental health coverage has yet to come in from the cold (Crisp et al, 2005; Nairn \& Coverdale, 2005). Psychiatrists are better placed than anyone else to change the climate, but some fear being ineffectual or misrepresented. One even likened the challenge to climbing Everest (Harrison, 1998), a view highlighted by a national newspaper survey of 306 health-related articles in which psychiatry coverage was four times more likely to be negative than coverage of general clinical medicine (Lawrie, 2000).

Headlines, such as 'MAD AXEMAN SCHIZO' are reported to symbolise society's fears and anxieties about the mind (Friedli, 1997). In one survey, almost $46 \%$ of all press coverage about mental health was about crime, harm to others and self-harm (54\% of tabloid coverage and almost $43 \%$ of broadsheet coverage (Friedli, 1997)).

Irresponsible reporting and the constraints of working with the media discourage good potential spokespeople even though overall publicity has been shown to work and generate significant benefit. This is why government, commerce and industry invest so much in it. What would happen if leading psychiatrists were to turn their backs on the press? London psychiatrist Dr Philip Timms put it this way: 'Psychiatrists should not be discouraged from talking to or writing for the media. If we do not represent our position, it will be misrepresented by the media'.

Effective communication can help to break down stigma. Effective 'media' communication is not necessarily the same thing as effective 'scientific' communication. A good scientific 'media' presenter should recognise that a news story does not necessarily begin at the 'scientific' beginning and end at the end. It is more likely to start at the 'end' and end with the beginning. Failure to recognise this is one of the most common reasons for communication failure and complaints that: 'They wouldn't let me explain the background'.

There is a good reason for the status quo. If each news story contained background information of the type physicians routinely provide for colleagues during scientific presentations, we would need wheelbarrows for our daily newspapers and the average broadcast interview would run to 10-15 min. Enough news already arrives at any large newspaper office or TV or radio station each day to fill four or five fat novels and flood news columns and air time several times over.

The interviewee also needs to know how much the audience needs to know. Think of this page as representing the sum total of your specialist knowledge. Now take a pin and insert it into any one of the words of the last sentence. That tiny pinprick of knowledge will probably represent all you need for a typical consumer media interview.

Deciding what the audience needs to know means understanding 'news values' and what makes news which explains the structure of the media training days I have run at the College.

A typical session with eight to ten participants includes:

- introductions

- how the media operate and what makes news

- key messages and soundbites

- preparing for an interview

- filmed and audio interviews with participants, followed by analysis.

\section{Introductions}

We begin by asking about media perceptions and experience and drawing up a list of possible interview topics for later in the day. This is an ice-breaking session. Most participants are nervous about 'performing' in front of colleagues - training can actually be more nervewracking than a live TV interview. However, pre-interview nerves do not seem to detract from overall enjoyment of the day. (The final evaluation form does not specifically ask if participants have enjoyed the day, but most seem to do so and accept inevitable mistakes as part of the learning experience - there is no better place to make mistakes than in a confidential training session.)

\section{What makes news?}

We all know what makes news, but what about why? Having a compelling story is not always enough. News never occurs in a vacuum, but within the context of the daily news agenda. There will only be so many health / medical stories each day. A story that is 'big' in the morning may disappear in the afternoon in the wake of a 'breaking' story - the biggest recent example of the past 50 years being $9 / 11$.

Timing is critical. For example, bowel cancer is of major importance, but this does not make it newsworthy. Wanting to break down the taboo of the disease, I planned an article about an epidemiological study, only to be told people would 'not want to read about bowel cancer over breakfast'. President Ronald Reagan then had a bowel cancer 'scare' and for 2-3 weeks, bowel cancer became big news despite the 'breakfast factor'. Reagan provided a so-called news peg. News is about today, tomorrow, last week, this week - not 6 months ago. Topical appeal can create 'short' windows of opportunity, 
making news from topics which may otherwise go unreported. One of the key messages of the sessions is that it is important to seize such opportunities as they arise, perhaps with the College press office or working in conjunction with your local trust. Being able to be 'proactive' is usually better than being 're-active' .

As so often, in the Reagan example it was an individual case history or story that made news, not the disease itself. Story-telling, one of the oldest forms of communication, is deeply embedded in our culture, and news stories are, above all else, about people. Local newspaper tycoon Sir Ray Tindle, whose group used to include 125 titles, has a mantra: 'No people, no news'.

Without case histories, many important stories are not published. A frequent concern on training days is that case history journalism will encourage 'anecdotal journalism'. This is not true if cases are put into context. For example, a psychiatrist might say that a particular case history 'is representative of many people who suffer from depression', or that another is an example of 'extreme suffering'. Psychiatrists also worry about confidentiality. Again, this is unfounded if case histories are restricted to anonymous broad brush strokes. This often becomes apparent in subsequent interview sessions which show how a basic case history can inject 'life' into an interview. Psychiatrists may also choose to refer journalists to self-help groups with members who are prepared (and often trained) to talk to the press.

\section{Features and benefits}

Many psychiatrists/doctors/scientists at the sessions initially fail to distinguish between so-called features and benefits. It is the 'benefits' of treatment which are important in most media interviews, not 'features', such as, for example, the mode of action of a particular antidepressant.

Think of yourself as a consumer with a new gas cooker. Its features may represent months of prizewinning research and development, but you may have no interest in how the gas reaches the saucepan or how the designer has cleverly varied the intensity of the heat. Your concern is with the end 'benefit' - cooked food - and whether or not the cooker is safe, cost-efficient and pleasing to the eye.

As newspaper readers, radio listeners, TV viewers we tend to be selfish and ask: 'What's in it for me? (Or those close to me?)'. There are, of course, exceptions. If Geoff Watts were interviewing you about antidepressant therapy on a radio science programme such as BBC Radio 4's Leading Edge, he may be intrigued about the mode of action of dual-action antidepressants. The key message here is: think audience and time constraints. Some interviewees spend so much time on features that there is no time for benefits. This is why so many interviewers interject with: 'What does this mean for the patient?' It is a way of asking the interviewee to switch the emphasis from features to benefits. Alternatively, many interviewees help out the reporter by saying: 'This means that...'.

\section{Key messages}

A key message is a take-home message, ideally short, snappy and simple. Think of 'the elevator test' - getting your message across between the first and third floors of a hotel, when the person you are talking to will get out. Allow 10-15s or so per message. Stick to two or three key messages in an interview. Key messages can either be simple statements of fact or wrapped up in soundbites - a short summary of the story. A vivid soundbite may provide a headline or a broadcast clip.

The paradox is that preparing a key message which is as simple as possible, but not any simpler, is notoriously hard and time-consuming. Psychiatrists, I suspect, spend far more time preparing presentations than media interviews, even though they will almost certainly have significantly more control over the former, at least until question time. Key messages should be supported by evidence - and perhaps a case history.

\section{Preparing for an interview}

Most interviewees are 'one-dimensional' and think: What's in it for me? Good interviewees think in three dimensions: What's good for the journalist? What's good for the audience? What's good for me? Of course, you cannot please all the people all of the time, but one dimensional thinking is unlikely to please anyone.

Everyday conversation conditions us to answer questions and - overall - we try and do an honest job. It is how we are conditioned from a very early age. A common error is to treat a media interview like an everyday conversation. Answering the interviewer's questions in full will stop you getting your key messages across in a short 2- or 3-min interview. The sessions highlight the considerable extent to which the scientific training of psychiatrists makes them susceptible to this trap.

\section{Building bridges}

The interviewee should try and take the initiative by using 'the $A B C$ of communication' (Acknowledge, Bridge, Communicate). They should acknowledge every question, without necessarily answering it. For example, you may acknowledge a question by saying: 'That's an interesting point, but l'd like to say. ..', 'You say that, but that's not quite right. . ' or, 'We don't think that's the case, we believe that...'. Phrases like these create verbal bridges from which the interviewee can communicate their key messages.

\section{Interviews}

Interviews and performance analysis take up most of the training days. Interviews are either recorded on tape recorder, mini-disk recorders (radio interviews) or filmed (TV interviews). This may seem inappropriate because 
(8)

special articles about $90 \%$ of media interviews are done on the phone, but the camera is widely recognised as a highly effective training tool, and it does give the sessions an additional sharp edge. All training interviews are restricted to about 4 min even though many print interviews may last significantly longer. The idea is to encourage participants to get their key messages across quickly, simply and succinctly. Each interview is analysed. Participants have the option to take home their own videotapes - which can be a source of amusement or concern. On seeing her father on screen at home, the daughter of one of my trainees asked: 'Daddy, why is that man being so horrible to you?'.

Do we try to be 'horrible'? The emphasis is on a broad-spectrum approach taking in the three main styles of interviewing: collaborative, 'informational' and confrontational. Overall, we try and make the sessions a little harder than they are likely to be in a live interview. Preparation is the key to success, but it is difficult to prepare without an understanding of what it is you are being prepared for - and it is better to be prepared for the worst possible scenario rather than being surprised by it.

\section{Declaration of interest}

J.I. runs an international healthcare communications coaching agency and has run 20 or so media training programmes at the College with the broadcaster Geoff Watts, under the direction of Deborah Hart, Head of External Affairs.

\section{References}

CRISP, A., GELDER, M. G., GODDART, E., et al (2005) Stigmatization of people with mental illness: a follow up study within the Changing Minds campaign of the Royal College of Psychiatrists. World Psychiatry, 4, 106-113.

FRIEDLI, L. (1997). Introduction to Making Headlines: Mental Health and the National Press. London: Health Education Authority.

LAWRIE S.M.(2000) Newspaper coverage of psychiatric and physical illness. Psychiatric Bulletin, 24, 104-106.

NAIRN, R. G. \& COVERDALE, J. H. (2005) People never see us living well: an appraisal of the personal stories about mental illness in a prospective print media sample. Australian and New

HARRISON,T. (1998) Climbing Mount Zealand Journal of Psychiatry, 39, 281Everest: tackling the media at regional level. Psychiatric Bulletin, 22, 111-112.

John Illman John Illman Communications (JIC), 9 Grand Avenue, London N10 3AY, e-mail: johnillman@blueyonder.co.uk 